\title{
Designing a resilient oil supply network with an intelligent solution algorithm
}

\author{
M. Rabbani*, S.M. Bahadornia and S.A. Torabi
}

School of Industrial and Systems Engineering, College of Engineering, University of Tehran, Tehran,, Iran

\begin{tabular}{l}
\hline C H R O N I C L E \\
\hline Article history: \\
Received December 18, 2014 \\
Accepted March 7 2015 \\
Available online \\
March 82015 \\
\hline Keywords: \\
Oil-supply disruption \\
Energy security \\
Resiliency \\
Scenario-based planning \\
Continuous facility layout \\
Meta-heuristic algorithm
\end{tabular}
\begin{abstract}
A B S T R A C T
Energy crisis in recent decades has demonstrated strong interdependence between national security and energy security. We are also witness of sever conflicts in oil-rich zones such as Middle-East and West of Suez. This study is the first attempt to provide a flexible multiobjective mathematical model which not only mitigates catastrophic risks by filtering and taking plausible oil-supply disruption scenarios into account, but also reduces oil-supply disruption probability by considering and optimizing political, economic and financial dimensions of oil procurement. Mentioned model determines a resilient portfolio of oil suppliers under each scenario and decides which ports or pipelines must be prepared for receiving oil. Furthermore, the proposed model in the second phase enhances oil-availability in crisis time by storing strategic oil stocks in appropriate geographic points. Also regarding to complexity of the second phase model, a meta-heuristic algorithm has been provided to solve the mentioned model. Finally validity of proposed model is checked by solving it for Greece case problem; sensitivity analysis shows that provided model significantly mitigates catastrophic risks threating energy security by balancing political affairs and reinforcing infrastructural facilities with the least possible cost.
\end{abstract}

\section{Introduction}

On one hand, Lesbirel (2013) mentions that security is the most important concern of nations, on the other hand Pasqualetti and Sovacool (2012) claim that security of nations strongly relies on security of their energy procurement. Also according to Berle et al. (2013), World Economic Forum (WEF) has introduced energy security as one of the major emergent global risks which results in social vulnerabilities. Manole et al. (2013) believe that the effects of a damage to a critical energy infrastructure are not only restricted to one country or region, but also it harms the international economy. International Energy Agency, IEA (2007), points out oil import dependency as one of the primary threats for energy security of nations; so Lesbirel (2013) warns that security of oil importing countries is threatened by disruptions in oil market which might lead to economic and social disasters. Unfortunately this peril is inevitable in short term and mid-term and decision makers in energy and security sector must consider the oil supply security as their first priority. Therefore it is essential to

* Corresponding author Tel.: +982188021067; fax: +982188013102

E-mail address: mrabani@ut.ac.ir (M. Rabbani) 
propose a comprehensive decision making framework in order to achieve a resilient oil supply network. Mentioned framework should include both restrictions and requirements of oil import and consider risk and resiliency factors of this area.

\subsection{Literature Review}

In order to develop a comprehensive model for resilient oil supply network, some leading studies in fields of oil security, supplier selection and risk management are reviewed in this section.

\subsubsection{Oil Security}

Energy is introduced by Blum and Legey (2012) as a key-element of economic development, therefore continuity, adequacy and affordability of energy supply must be guaranteed.

Das et al. (1990) introduce disruptive sources threatening global oil market, including natural disasters, economic volatility, political instability and war. For instance, Yadlin and Guzansky (2012) and Manole et al. (2013) mention that major portion of energy containers (oil and gas) are passing through the riskiest regions of the world; at the same time energy facilities are one of terrorists' main targets. Lesbirel (2013) states that we have learnt from past that political and social attributes of countries involved in global oil supply network must be considered, whether a country is an oil supplier or an intermediate in this network. Also Clarke et al. (2012) claim that regional, political and social factors play an important role in maintaining energy supply security. Zhang et al. (2013) provided a supply chain-based framework to evaluate oil import security which illustrates that external supply has been transformed to a new risk. Sovacool \& Mukherjee (2011) have introduced dependency, diversification, safety, reliability and resiliency as components of supply security. Johansson (2013) proposed a comprehensive typology to cover the mutual interaction between energy and security, also Sovacool et al. (2011) provide an indicator for energy security assessment.

\subsubsection{Supplier Selection}

According to a comprehensive survey by Ho et al. (2010), one of the most important criteria for supplier selection is risk measures. Regarding to importance of risk mitigation in supplier selection, Sawik (2010), Sawik (2011a) and Sawik (2011b) have provided supplier selection models with various assumptions using Value at Risk (VaR) and Conditional Value at Risk (CVaR). However international politics do not affect imports in United States, Mityakov et al. (2012) believe that petroleum products are exceptions. Therefore correlation of economic and geopolitical interests between involved countries in supply network must be taken into account.

\subsubsection{Risk Management}

Briggs et al. (2012) have categorized petroleum supply chain risks in four categories: source dependence, facility dependence, transit dependence and structural risks. Briggs et al. (2012) and Haldar et al. (2012) claim that past experiences demonstrate that actions for reducing probability of risks are as essential as actions for managing consequences of risks. Also according to Grossi \& Kunreuther (2005) and Pettit (2008) we have learnt from past that maximum loss of catastrophic events is significantly greater than mean or median of their loss. Pettit (2008) and Haldar et al. (2012) state that resiliency not only reduces probability of disruptions but also enhances ability of a system in recovering from disruptions.

\subsection{Research Gap and Problem Description}

On one hand Blum and Legey (2012) mention that energy security is not a new concept, but it requires new approach which covers both supply security and demand security; on the other hand Despite the efficiency and necessity of using mathematical programming and optimization in order to safeguard oil supply security; to the best of our knowledge there is no study to fill this gap. This article is seeking to 
reduce the probability of disruption for an oil net-importer country and prepare it for recovering rapidly from an oil-supply disruption which means having a resilient oil supply network. Therefore, in the first phase a novel applicable model has been proposed which takes economic, political and resiliency factors into account in addition to satisfaction of technical requirements. Authors have utilized multiobjective programming in order to achieve following goals:

- Minimizing catastrophic risk using CVaR approach;

- Mitigating vulnerability by maximizing dependency of supplier countries to oil-export incomes;

- Minimizing political risk of suppliers;

- Select a secure and efficient portfolio of oil suppliers and determining oil entry points from each supplier under each scenario.

In order to achieve mentioned goals, the supply risk management approach proposed by Zeng et al. (2005) has been used in this paper. Steps of mentioned risk management method are given in Table 1.

Table 1

Supply risk management steps Zeng et al. (2005)

\begin{tabular}{cc}
\hline Management Process & Techniques \\
\hline \multirow{2}{*}{ Risk Identification } & Scenario Analysis \\
& Process Mapping \\
& Cost-Benefit Analysis \\
\hline \multirow{2}{*}{ Risk Assessment } & Decision Trees \\
& Simulation \\
\hline \multirow{2}{*}{ Risk Prioritization } & Sensitivity Analysis \\
& Discounted Cash Flow Analysis \\
\hline \multirow{2}{*}{ Risk Management } & Probability of Occurrence \\
& Severity of Impact \\
& Supplier Choice \\
& Diversification \\
& Stockpiling \\
& Pooling Resources \\
& Legal Actions \\
\hline
\end{tabular}

In the second phase, a general non-linear mathematical model has been proposed in order to assign location of strategic oil-storage terminals considering availability and security matters. Due to the complexity of proposed model, a novel meta-heuristic algorithm has been provided to solve the mentioned model.

\section{Risk Analysis}

\subsection{Risk Identification}

As mentioned by Beccue and Huntington (2005) plausible scenarios of oil disruption in short period (up to 6 months) and their probability are brought in Table 2.

Table 2

Each supplier's magnitude and probability of disruption (Beccue \& Huntington, 2005)

\begin{tabular}{ccccc}
\hline Region & $\mathrm{P}(\mathrm{No})$ & $\mathrm{P}($ Small $)$ & $\mathrm{P}($ Medium $)$ & $\mathrm{P}(\mathrm{All})$ \\
\hline Saudi Arabia & 0.5 & 0.35 & 0.11 & 0.04 \\
Other Persian Gulf & 0.11 & 0.7 & 0.17 & 0.02 \\
West of Suez & 0.2 & 0.6 & 0.2 & 0 \\
Caspian Sea & 0.75 & 0.2 & 0.05 & 0 \\
\hline
\end{tabular}

Magnitude of each disruption is defined by Beccue and Huntington (2005) in Table 3. 
Table 3

Disruption amount (Beccue \& Huntington, 2005)

\begin{tabular}{ccc}
\hline Shortfall Description & Disruption Interval (\% of Supply) & Disruption Value (\% of Supply) \\
\hline No Shortfall & $0-10$ & 5 \\
Small Shortfall & $10-30$ & 20 \\
Medium Shortfall & $30-80$ & 50 \\
All & $80-100$ & 90 \\
\hline
\end{tabular}

\subsection{Risk Assessment and Prioritization}

According to each scenario and its corresponding probability which is mentioned in Table 2, there are potentially 256 oil disruption scenarios; while number of scenarios must be reduced to about 10 scenarios as Haimes (2004) suggested. Therefore risk-filtering approach proposed by DoD (2000) is utilized to exploit important scenarios. Required definitions for this approach are brought in Table 4 and Table 5.

Table 4

Probability description DoD (2000)

\begin{tabular}{cc}
\hline Likelihood & Probability \\
\hline Frequent & $0.1<\mathrm{P}$ \\
Probable & $0.01<\mathrm{P}<0.1$ \\
Occasional & $0.001<\mathrm{P}<0.01$ \\
Remote & $0.000001<\mathrm{P}<0.001$ \\
Improbable & $\mathrm{P}<0.000001$ \\
\hline
\end{tabular}

Table 5

Consequence description

\begin{tabular}{cc}
\hline Consequence & Characteristic \\
\hline Catastrophic & At least one "All" \\
Critical & At least one "Medium" \\
Marginal & At least two "Small" \\
Negligible & Else \\
\hline
\end{tabular}

Regarding to what mentioned by DoD (2000), 13 scenarios lies into the High-priority zone, which are illustrated in Table 6:

\section{Table 6}

The most important disruption scenarios

\begin{tabular}{llllllll}
\hline No. & Saudi & Gulf & Suez & Caspian & Probability & Likelihood & Consequence \\
\hline $\mathbf{1}$ & No & Small & Small & Medium & 0.0105 & Probable & Critical \\
$\mathbf{2}$ & No & Small & Medium & No & 0.0525 & Probable & Critical \\
$\mathbf{3}$ & No & Small & Medium & Small & 0.014 & Probable & Critical \\
$\mathbf{4}$ & No & Medium & No & No & 0.01275 & Probable & Critical \\
$\mathbf{5}$ & No & Medium & Small & No & 0.03825 & Probable & Critical \\
$\mathbf{6}$ & No & Medium & Small & Small & 0.0102 & Probable & Critical \\
$\mathbf{7}$ & No & Medium & Medium & No & 0.01275 & Probable & Critical \\
$\mathbf{8}$ & Small & Small & Medium & No & 0.03675 & Probable & Critical \\
$\mathbf{9}$ & Small & Medium & Small & No & 0.026775 & Probable & Critical \\
$\mathbf{1 0}$ & Medium & Small & No & No & 0.01155 & Probable & Critical \\
$\mathbf{1 1}$ & Medium & Small & Small & No & 0.03465 & Probable & Critical \\
$\mathbf{1 2}$ & Medium & Small & Medium & No & 0.01155 & Probable & Critical \\
$\mathbf{1 3}$ & All & Small & Small & No & 0.0126 & Probable & Catastrophic \\
\hline
\end{tabular}

Note that sum of probabilities in Table 6 is 0.285 , so probability of regular condition is 0.715 . 


\section{Model Description}

\subsection{First Phase: Mathematical Modeling for Oil-Supply Risk Management}

In this section a flexible multi-objective mathematical model is provided which not only selects the best portfolio of oil suppliers and their share under each scenario, but also determines appropriate entry points for importing oil and amount of oil imported through each entry point under each scenario.

Following assumptions have been made for the first phase model formulation:

- In order to maintain generality of proposed model, the term "oil" in this study refers to crude oil and its derivatives. To convert oil derivatives to their crude oil equivalent, coefficients mentioned in

- $\quad$ Table 7 which are suggested by IEA (2007) are used.

Table 7

Crude oil equivalents of oil derivatives IEA (2007)

\begin{tabular}{cc}
\hline Product & Coefficient \\
\hline crude oil (deducting naphtha) & 0.96 \\
oil product (excluding naphtha) & 1.065 \\
gasoline and naphtha & 1.2 \\
middle distillates & 1.2 \\
heavy fuel oil & 1.2 \\
\hline
\end{tabular}

- Generality and simplicity of cost terms are achieved through using major oil transportation costs mentioned by Pootakham and Kumar (2010) which are categorized in

- $\quad$ Table 8.

\section{Table 8}

Major cost components of oil transportation types (Pootakham \& Kumar, 2010)

\begin{tabular}{cccc}
\hline Transportation Type & Fixed Cost & Incurred time & Variable Cost \\
& Construction & Initial & \\
Pipeline & Insulation & Initial & Pump power \\
& Maintenance & Annual & Annual \\
Tanker & Operational & Initial & Distance
\end{tabular}

- Oil supplier selection is a strategic decision problem which makes it a long-term issue; therefore time-value of money is taken into account and all annual costs are converted to their present value equivalent by discount factor calculated in Eq. (1).

$$
\sum_{t=1}^{T}(1+g)^{t} \times(1+i r)^{-t}=\left[\frac{1-\left(\frac{1+g}{1+i r}\right)^{T+1}}{\frac{i r-g}{1+i r}}\right]
$$

where $T$ is length of planning horizon, $g$ is annual growing factor of costs and ir is annual interest rate.

- Brown and Kennelly (2013) state that oil-producing countries can counterbalance interests of oil-importing countries by oil revenues. So according to Shaffer (2013) as dependency of suppliers' Gross Domestic Product (GDP) on oil-export increases, oil security of oil-importing 
country increases. Consequently maximizing oil-dependency of selected suppliers is an objective of proposed model.

- According to Jansen et al. (2004), OECD (2007), Mansson et al. (2012) and Chuang \& Ma (2013), diversification is the best policy to mitigate losses when we have no knowledge about disruptive events. Consequently, in order to achieve supplier diversity, "co-vary diversity reliability index" calling $\mathrm{HHI}_{3}$ suggested by Chuang and Ma (2013) is supposed to be minimized in provided model.

- In this study, CVaR is the indicator of catastrophic risk which is conditional expected loss. For more details about CVaR, (see Rockafellar \& Uryasev, 2002).

- Strategic decision variables have identical values in all scenarios while values of tactical decision variables change by the variation of scenarios.

- As mentioned by Le Coq and Paltseva (2009) switching between ports is much easier than pipelines. Therefore in order to satisfy resiliency conditions, Jewell (2011) suggests to have at least 5 oil-importing ports or 9 oil pipelines. Consequently this condition has been taken into account in the following model.

- Since Morrow et al. (1998) claim that democracy in both supplier and consumer countries raises trade and leads to peace, weighted average democracy level of selected oil-importing countries must meet a minimum level.

\subsection{Model Description}

Sets:

$I$

$J$

$S$

$\Theta$

Parameters:

depi $_{i}$

$\sigma_{i k}$

A

$\pi \theta$

CC

$P p$

$F C L_{i}^{s}$

G

Ir

$T$

$d l_{i}$

C

NI

$F C T_{i j}$

$\operatorname{Cap}_{i \theta}$

$V_{s}$

resp

resı

TUC

demi $_{i}$
Set of potential oil supplier countries;

Set of potential oil receiver ports in demanding country;

Set of pipeline capacities;

Set of plausible oil disruption scenarios.

Dependency of $i^{\text {th }}$ supplier's GDP to oil export;

Mutual conflict between supplier $i$ and $k$;

Loss percentile exceeds VaR;

Realization probability of $\theta^{\text {th }}$ scenario;

Cost of contracting with each supplier;

Port preparation cost for receiving oil;

Fixed Cost of pipeline with capacity $s$ from supplier $i$;

Annual cost increase gradient;

Annual interest rate;

Length of planning horizon;

Length of pipeline from $i^{\text {th }}$ supplier to demanding country;

Electricity cost for pumping one barrel (159 liter) of oil along one kilometer via pipeline;

Annual oil net import of demanding country;

Cost of each oil truck travel from supplier $i$ to $j^{\text {th }}$ port of demanding country;

Annual export capacity of supplier $i$ under scenario $\theta$;

Annual capacity of $s^{\text {th }}$ type of oil pipeline;

Minimum number of ports required to have a resilient oil supply

networks (5);

Minimum number of pipelines required to have a resilient oil

supply networks (9);

Capacity of one oil carrying truck;

Democracy score of supplier $i$; 
Minimum aspiration level of overall democracy degree of selected Dem $_{\min } \quad$ oil supplier countries.

Variables:

$x_{i \theta}$

$\operatorname{VaR}$

$T_{\theta}$

$w_{i}$

$y j$

$y l_{i}^{s}$

$t x l_{i \theta}$

$N C_{i j \theta}$

$x p_{i j \theta}$

$x l_{i \theta}{ }^{s}$

$q_{i j \theta}$

$\mathrm{Z}_{1}, \mathrm{Z}_{2}$
Share of oil being imported from supplier $i$ under scenario $\theta$ in total oil import;

Value at Risk;

Tail cost for scenario $\theta$;

1 if contract with $i^{\text {th }}$ supplier is signed, 0 else;

1 if port $j$ is selected as an oil importing port, 0 else;

1 if pipeline with capacity $s$ is constructed from supplier $i, 0$ else;

Proportion of oil imported from supplier $i$ via pipeline under scenario $\theta$;

Number of Carriers annually transport oil from supplier $i$ to port $j$ of demanding country under scenario $\theta$.

Proportion of oil imported from supplier $i$ via port $j$ under scenario $\theta$;

Proportion of oil imported via pipeline with capacity $s$ from supplier $i$ under scenario $\theta$;

Auxiliary variable;

Resiliency guarantee binary variables.

Model:

$$
\begin{aligned}
& \operatorname{maxOil}_{\text {Dep }}=\sum_{\theta} \sum_{i} \operatorname{dep}_{i} \times x_{i \theta} \\
& \min \mathrm{HHI}_{3}=\sum_{i} \sum_{k \leq i} \sum_{\theta} \sigma_{i k} \times x_{i \theta} \times x_{k \theta} \\
& \operatorname{minCVaR}=\operatorname{VaR}+(1-\alpha)^{-1} \times \sum_{\theta} \pi_{\theta} \times T_{\theta}
\end{aligned}
$$

subject to

$$
\begin{aligned}
& \sum_{i} C C \times w_{i}+\sum_{j} p p \times y_{j}+\sum_{i} \sum_{s} F C L_{i}^{s} \times y l_{i}^{s}+\left[\frac{1-\left(\frac{1+g}{1+i r}\right)^{T+1}}{\frac{i r-g}{1+i r}}\right] \\
& \times\left[\sum_{i} d l_{i} \times C \times t \times l_{i \theta} \times N I+\sum_{i} \sum_{j} F C T_{i j} \times N C_{i j \theta}\right]-V a R-T_{\theta} \leq 0 \quad \forall \theta \\
& \sum_{i} X_{i \theta}=1 \quad \forall \theta \\
& N I \times x_{i \theta} \lesssim \operatorname{Cap}_{i \theta} \times w_{i} \quad \forall i, \theta \\
& \sum_{i} x p_{i j \theta} \leq y_{j} \quad \forall j, \theta \\
& N I \times x l_{i \theta}^{s} \leq V_{s} \times y l_{i}^{s} \quad \forall i, s, \theta \\
& \sum_{s} x l_{i \theta}^{s}=t x l_{i \theta} \quad \forall i, \theta \\
& x_{i \theta}=t x l_{i \theta}+\sum_{j} x p_{i j \theta} \quad \forall i, \theta
\end{aligned}
$$




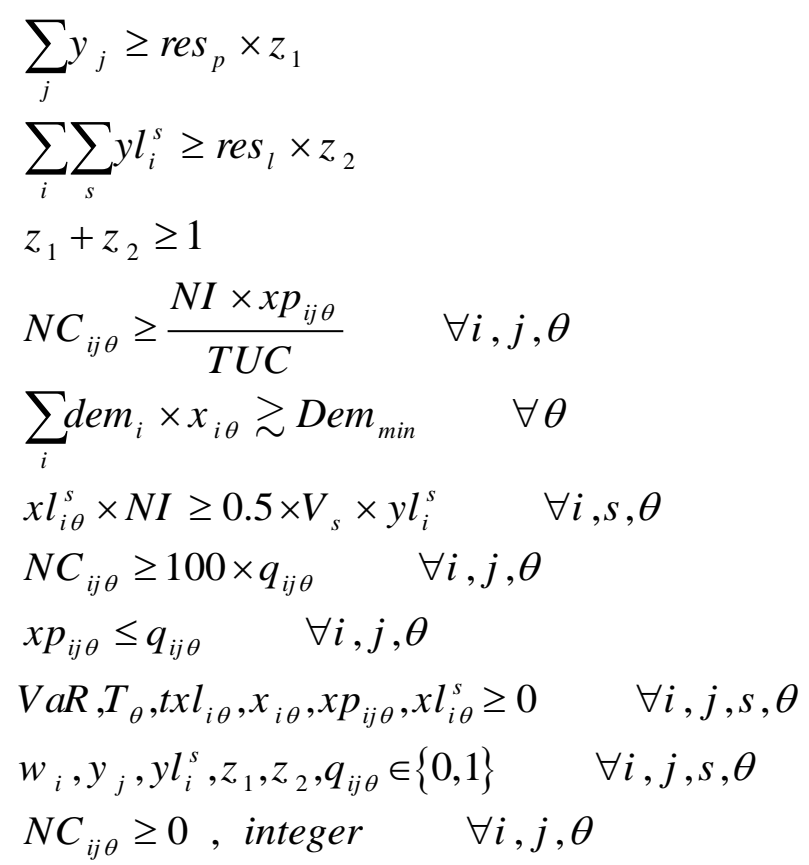

Eq. ( 2) maximizes weighted average dependency of selected oil suppliers on oil export; Eq. (3) minimizes modified Herfindhal-Hirschman Index in order to satisfy diversity considering individual and mutual risks of suppliers; Eq. (4) minimizes $\alpha$-percent Conditional Value at Risk; Eq. ( 5) calculates tale cost for each scenario; Eq. ( 6) Guarantees that all oil import requirement would be met under each scenario; Eq. ( 7) assures that oil import from each supplier does not happen unless contract is signed with corresponding supplier, in addition imported oil from each supplier under each scenario will not exceed its export capacity; Eq. ( 8) maintains that oil cannot be imported via any port under any scenario unless corresponding port has been prepared; Eq. (9) does not allow oil import via pipeline more than its capacity; Eq. ( 10) calculates total amount of oil imported via pipeline in each scenario; Eq. ( 11) computes total amount of oil imported from each supplier, whether via port or pipeline, in each scenario; Eq. ( 12), Eq. ( 13) and Eq. ( 14) maintain oil supply resiliency conditions; Eq. ( 15) guarantees sufficiency of number of oil carrying trucks; Eq. ( 16) Assures that weighted average democracy score of selected suppliers must be more than a pre-defined minimum level; Eq. (17), Eq. (18) and Eq. ( 19) prevent resulting inefficient solution vectors when the problem is being solved for Oil-dependency and $\mathrm{HHI}_{3}$ objective functions regardless of incurred costs; Eq. ( 20), Eq. ( 21) and Eq. (22) determine domain of decision variables.

\subsection{Second Phase: Location of Oil Storage Terminals}

In the previous section, security of oil supply network has been guaranteed from outbound aspects; while proposed model in this section maintains security of oil storage terminals. Proposed model in this section is based on following assumptions:

- According to the IEA standard, IEA (2007), oil net importer countries require to increase their emergency oil reserve to at least 90 days of maximum net import.

- In order to maintain the generality of proposed model, power of distances has been considered as a parameter which could be assigned by decision maker.

- Since by increasing capacity of terminals, importance of objectives increase, importance of proposed objective functions is proportional to square of terminal capacities.

\section{Indices and Sets:}

$M$

$n g n^{\prime}$

K
Index of oil-receiving ports $(m=1, . ., M)$;

Index of oil-storage terminals $\left[n\left(n^{\prime}\right)=1, \ldots, N\right] ;\left(2 \leq N \leq\left[\frac{T S}{C a p_{\text {min }}}\right]\right)$

Index of oil-importing country refineries $(k=1, \ldots, K)$; 


\section{Parameters:}

$\lambda$

$w p$

$w r$

$\operatorname{lgp}_{m}$

$l t p_{m}$

$a_{m}$

$\operatorname{lgr}_{k}$

$l r_{k}$

$b_{k}$

$P$

TS

Cap $_{\min }$

$L g_{\min }$

$L g_{\max }$

$L t_{\text {min }}$

$L t_{\max }$
Weight of objective function related to minimization of sum of distances

between terminals and both ports and refineries $(0 \leq \lambda \leq 1)$;

Importance of adjacency between terminals and ports;

Importance of adjacency between terminals and refineries $(w p+w r=1)$;

Longitude of port $m$;

Latitude of port $m$;

Importance of port $m$ for adjacency to oil-storage terminals $\left(\sum_{m=1}^{M} a_{m}=1\right)$;

Longitude of refinery $k$;

Latitude of refinery $k$;

Importance of refinery $k$ for adjacency to oil-storage terminals $\left(\sum_{k=1}^{K} b_{k}=1\right)$;

Power of distance terms;

Total amount of oil required for storage (barrels);

Minimum capacity of an oil-storage terminal (barrels);

Minimum allowed longitude for construction of an oil-storage terminal;

Maximum allowed longitude for construction of an oil-storage terminal;

Minimum allowed latitude for construction of an oil-storage terminal;

Maximum allowed latitude for construction of an oil-storage terminal;

\section{Decision Variables}

$\operatorname{lgt}_{n} \quad$ Longitude of $n^{\text {th }}$ oil-storage terminal;

$l_{n} \quad$ Latitude of $n^{\text {th }}$ oil-storage terminal;

$\xi_{n}, \xi_{n^{\prime}} \quad$ Capacity of $n\left(n^{\prime}\right)^{\text {th }}$ oil-storage terminal (barrels);

Model:

$$
\begin{aligned}
& \min D_{1}=\sum_{m=1}^{M} \sum_{n=1}^{N} a_{m}\left(\left|l g t_{n}-l g p_{m}\right|^{p}+\left|l t t_{n}-l t p_{m}\right|^{p}\right)^{\frac{1}{p}} \times\left(\frac{\xi_{n}}{T S}\right)^{2} \\
& \min D_{2}=\sum_{n=1}^{N} \sum_{k=1}^{K} b_{k}\left(\left|l g r_{k}-l g t_{n}\right|^{p}+\left|l t r_{k}-l t t_{n}\right|^{p}\right)^{\frac{1}{p}} \times\left(\frac{\xi_{n}}{T S}\right)^{2} \\
& \max D_{3}=\sum_{n=1}^{N-1} \sum_{n=n+1}^{N}\left(\left|l g t_{n^{\prime}}-l g t_{n}\right|^{p}+\left|l t t_{n^{\prime}}-l t t_{n}\right|^{p}\right)^{\frac{1}{p}} \times\left(\frac{\xi_{n}}{T S}\right)\left(\frac{\xi_{n^{\prime}}}{T S}\right) \\
& \min D=\lambda\left(w p \cdot D_{1}+w r . D_{2}\right)-(1-\lambda) D_{3}
\end{aligned}
$$

subject to

$$
\begin{aligned}
& \sum_{n=1}^{N} \xi_{n}=T S \\
& \xi_{n} \geq \operatorname{Cap}_{\text {min }} \quad \forall n \\
& L g_{\text {min }} \leq l g t_{n} \leq L g_{\text {max }} \quad \forall n \\
& L t_{\text {min }} \leq l t t_{n} \leq L t_{\text {max }} \quad \forall n \\
& l g t_{n}, I t t_{n}, \xi_{n} \geq 0 \quad \forall n
\end{aligned}
$$

Eq. (23) minimizes weighted sum of distance of oil-storage terminals from oil-receiving ports. Eq. (24) minimizes weighted sum of distance of oil-storage terminals from refineries. Eq. (25) maximizes weighted geographic dispersion of oil-storage terminals. As measuring units of three mentioned objective functions are identical, Eq. (26) transforms proposed multi-objective model into a singleobjective one. Constraint (27) guarantees that enough capacity for oil storage would be constructed. Constraint (28) maintains capacity of oil-storage terminals at a minimum economic level. Constraints 
(29) and (30) guarantees that location of oil-storage terminals will be in the acceptable geographic region. (31) Assigns domain of decision variables.

\section{Solution Method}

\subsection{Crisp Single-Objective Equivalent Model}

We are encountered with a fuzzy multi-objective model where each objective has its distinct measuring unit and importance. So the interactive programming approach provided by Torabi \& Hassini (2008) calling $\mathrm{TH}$ approach is used in this study. Also fuzzy constraints are transformed to their crisp equivalent according to Eq. (32) and Eq. (33).

$$
\begin{aligned}
& A X \lesssim b \rightarrow A X \leq b+(1-\beta) t \\
& A X \gtrsim b \rightarrow A X \geq b-(1-\beta) t
\end{aligned}
$$

where $\beta$ is satisfaction level of soft constraints and $t$ is the maximum tolerable deviation from desirable right hand side value.

\subsection{Proposed Meta-Heuristic Algorithm For Second Phase Model}

Regarding to the complexity of proposed model in the second phase, a meta-heuristic algorithm based on Deferential Evolutionary (DE) has been designed and provided in this section. DE is a populationbased algorithm introduced by Storn and Price (1997), it has five main factors: solution representation, initial population, mutation, offspring and selection. Notations used in the proposed algorithm are as follows:

$\begin{array}{ll}N P & \text { Size of population; } \\ \text { ii } & \text { Index of population in each generation }(\mathrm{ii}=1, \ldots, \mathrm{NP}) ; \\ G_{\max } & \text { Number of generations; } \\ g g & \text { Index of generation }\left(\mathrm{gg}=1, \ldots, \mathrm{G}_{\max }\right) ; \\ O_{\text {ii,gg }} & \text { The } i i^{\text {th }} \text { population in the } g g^{\text {th }} \text { generation; } \\ \text { rand}[0,1] & \text { A random number between } 0 \text { and } 1 \text { with uniform distribution; } \\ N & \text { Number of oil-storage terminals. }\end{array}$

\subsubsection{Solution Representation}

Each solution has been illustrated by a $3 \times \mathrm{N}$ matrix which is shown in Fig. $\mathbf{1}$.

$$
\left[\begin{array}{ccccc}
\operatorname{lgt}_{1} & \cdots & \operatorname{lgt}_{n} & \cdots & \operatorname{lgt}_{N} \\
\operatorname{ltt}_{1} & \cdots & l t t_{n} & \cdots & \operatorname{ltt}_{N} \\
\xi_{1} & \cdots & \xi_{n} & \cdots & \xi_{N}
\end{array}\right]
$$

Fig. 1. Solution representation of the proposed DE algorithm

Therefore each generation is a three-dimensional matrix with $\mathrm{NP} \times 3 \times \mathrm{N}$ elements. The schematic view of each generation is illustrated in Fig. 2. 


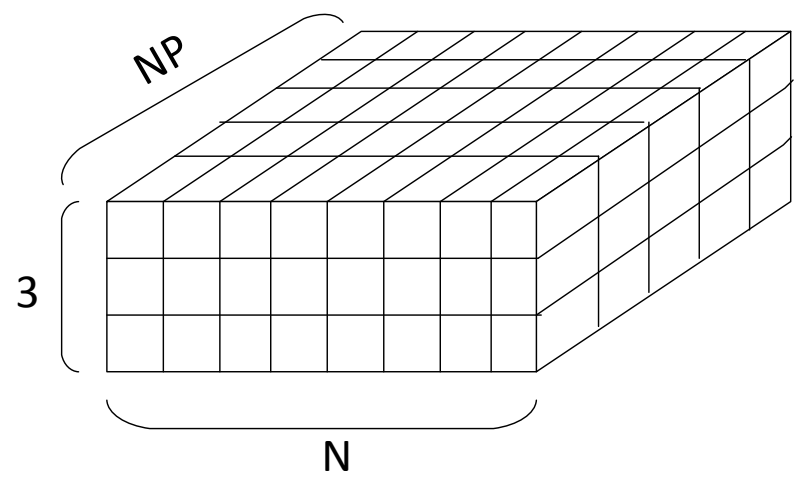

Fig. 2. Schematic view of a generation

\subsubsection{Initial Population}

In order to generate feasible members for initial population, following procedure has been utilized for decision variables:

$$
\begin{aligned}
& l g t_{i i, g g}=L g_{\text {min }}+\left(L g_{\text {max }}-L g_{\text {min }}\right) \text { rand }[0,1] \\
& L t t_{i i, g g}=L t_{\text {min }}+\left(L t_{\text {max }}-L t_{\text {min }}\right) \text { rand }[0,1] \\
& \xi_{i i, g g}=\operatorname{rand}[0,1] \rightarrow \xi_{i i, g g}=\frac{\operatorname{Cap}_{\text {min }}}{T S}+\left(1-N \frac{\operatorname{Cap}_{\min }}{T S}\right) \frac{\xi_{i i, g g}}{\sum_{n=1}^{N} \xi_{i i, g g}}
\end{aligned}
$$

\subsubsection{Mutation}

Mutation operation is performed in order to create variety in solutions and consequently avoid local optimums. For mutation operator in DE, it is required to opt-out three random members ( $\left.\mathrm{rr}_{1}, \mathrm{rr}_{2}, \mathrm{rr}_{3}\right)$ and then calculate the mutation vector as follows:

$$
\Delta_{i i, g g}=O_{r_{1}, g g}+\tau\left(O_{r_{2}, g g}-O_{r_{3}, g g}\right)
$$

where $\tau$ is the mutation factor between 0 and 1 .

\subsubsection{Off-Spring}

According to DE algorithm, elements of each new population are selected by the following rule:

$$
\Psi_{k k, i i, g g}=\left\{\begin{array}{cr}
\Delta_{k k, i i, g g} & \text { if }(\text { rand }[0,1] \leq C R) \text { or } k k=\varphi, \\
O_{k k, i i, g g} & \text { otherwise. }
\end{array}\right.
$$

where CR is the constant off-spring parameter and it is between 0 and 1 . It is notable that $\varphi$ is a random number which results in at least one mutated element in new members. Since mutation and off-spring operators might generate infeasible solutions, mentioned procedure in Fig. $\mathbf{3}$ has been utilized to make the obtained solutions feasible.

\subsubsection{Selection}

The first step in generating a new population for a new generation is selection. In the proposed algorithm, value of objective function for each generated solution is compared with its corresponding solution and more befitting solution vector transfers to the next generation. 


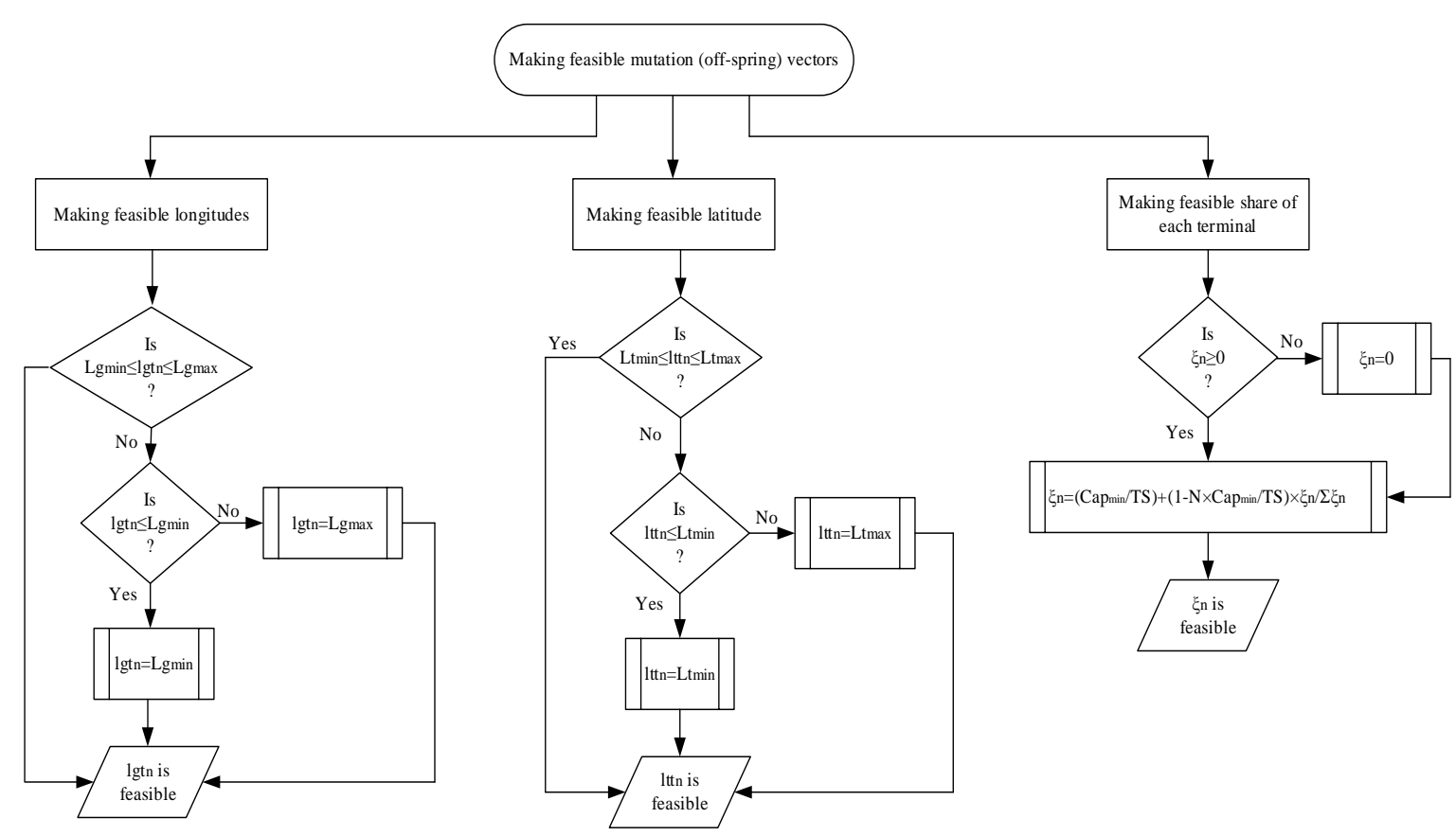

Fig. 3. Making feasible mutation (off-spring) vectors

\section{Numerical Example}

Since proposed model in this study is for an oil net importer and according to Pachiu (2013), energy supply is the major concern of European Union (EU) in field of energy security; authors have chosen Greece to verify the provided model.

\subsection{Data Gathering}

However there are about 125 oil-exporting countries, regarding to CIA (2009) 20\% percent of suppliers have $80 \%$ of market share round the world. Consequently in this study only major oil-exporters are considered as potential oil suppliers. Required characteristics of potential suppliers including Dependency of their GDP on oil-export, Length of a potential oil pipeline from suppliers to Greece and Democracy score of each oil-exporter; are stated in Table A. 1. Note that democracy score varies from 1 for full-dictatorship to 10 for ideal democracy. Mutual conflicts between each two suppliers depicted in Table A. 2 are adapted by subtracting correlation proposed by Voeten (2012-08) from 1. Mentioned conflict ranges from 0 to 2 as its lowest and highest values respectively. According to CIA (2009) net import of oil by Greece is 181259000 barrels per year. Authors have also considered length of planning horizon 10 years; growth rate of annual cost $10 \%$, annual interest rate $15 \%$ and minimum aspiration level of democracy 2 units. In order to defuzzify constraint (7) a tolerance level is required for export capacity of oil-suppliers. So excess capacities provided in Table A. 4 are used as tolerance level. These values are proportional to values brought in Table A. 3. Among all available ports of Greece, in this study seven ports have been chosen as potential candidate entry points for importing oil: Korinthos, Messolongi, Patra, Pireas, Preveza, Thessaloniki and Volos.

Approximate costs of carrying one oil truck from oil-exporters to each port is calculated for 350\$/kM and 2000\$ for loading/unloading which are provided in Table A. 5. Moreover three pipeline capacities are considered: 100000, 200000 and 400000 barrels per day, where construction cost of each type from each exporter is given in Table A. 6. Contraction cost with an exporter is considered $500000 \$$ and cost for preparing a port for importing oil is considered 1000000000 . Electricity cost of pumping one barrel oil along one kilometer is considered 15.9\$. Capacity of each oil carrying truck is considered 20000 barrels. According to what mentioned in section 2.2, capacity of each supplier under each scenario and corresponding probability are provided in Table 9. 
Table 9

Probabilities and Capacities of each scenario (million barrels per year)

\begin{tabular}{|c|c|c|c|c|c|c|c|c|c|c|c|c|c|c|}
\hline Supplier & & & & & & & Sce & ario & & & & & & \\
\hline & 1 & 2 & 3 & 4 & 5 & 6 & 7 & 8 & 9 & 10 & 11 & 12 & 13 & 14 \\
\hline Algeria & 494.6 & 309.2 & 309.2 & 587.4 & 494.6 & 494.6 & 309.2 & 309.2 & 494.6 & 587.4 & 494.6 & 309.2 & 494.6 & 618.3 \\
\hline Angola & 540.5 & 270.2 & 135.1 & 128.4 & 102.7 & 82.2 & 41.1 & 20.5 & 16.4 & 15.6 & 12.5 & 6.2 & 5 & 675.6 \\
\hline India & 301.3 & 301.3 & 301.3 & 301.3 & 301.3 & 301.3 & 301.3 & 301.3 & 301.3 & 301.3 & 301.3 & 301.3 & 301.3 & 301.3 \\
\hline Iran & 736.7 & 736.7 & 736.7 & 460.4 & 460.4 & 460.4 & 460.4 & 736.7 & 460.4 & 736.7 & 736.7 & 736.7 & 736.7 & 920.9 \\
\hline Iraq & 633.6 & 633.6 & 633.6 & 396 & 396 & 396 & 396 & 633.6 & 396 & 633.6 & 633.6 & 633.6 & 633.6 & 792.1 \\
\hline Kazakhstan & 253.7 & 482 & 405.9 & 482 & 482 & 405.9 & 482 & 482 & 482 & 482 & 482 & 482 & 482 & 507.4 \\
\hline Kuwait & 621.1 & 621.1 & 621.1 & 388.2 & 388.2 & 388.2 & 388.2 & 621.1 & 388.2 & 621.1 & 621.1 & 621.1 & 621.1 & 776.4 \\
\hline Libya & 461.4 & 230.7 & 115.3 & 109.6 & 87.7 & 70.1 & 35.1 & 17.5 & 14 & 13.3 & 10.7 & 5.3 & 4.3 & 576.7 \\
\hline Malaysia & 235.4 & 235.4 & 235.4 & 235.4 & 235.4 & 235.4 & 235.4 & 235.4 & 235.4 & 235.4 & 235.4 & 235.4 & 235.4 & 235.4 \\
\hline Norway & 797.2 & 797.2 & 797.2 & 797.2 & 797.2 & 797.2 & 797.2 & 797.2 & 797.2 & 797.2 & 797.2 & 797.2 & 797.2 & 797.2 \\
\hline Qatar & 303.1 & 303.1 & 303.1 & 189.4 & 189.4 & 189.4 & 189.4 & 303.1 & 189.4 & 303.1 & 303.1 & 303.1 & 303.1 & 378.9 \\
\hline Russian Federation & 914.3 & 1737.2 & 1462.9 & 1737.2 & 1737.2 & 1462.9 & 1737.2 & 1737.2 & 1737.2 & 1737.2 & 1737.2 & 1737.2 & 1737.2 & 1828.7 \\
\hline Saudi Arabia & 2647.4 & 2647.4 & 2647.4 & 2647.4 & 2647.4 & 2647.4 & 2647.4 & 2229.4 & 2229.4 & 1393.4 & 1393.4 & 1393.4 & 278.7 & 2786.8 \\
\hline UAE & 699.3 & 699.3 & 699.3 & 437.1 & 437.1 & 437.1 & 437.1 & 699.3 & 437.1 & 699.3 & 699.3 & 699.3 & 699.3 & 874.2 \\
\hline USA & 700.8 & 700.8 & 700.8 & 700.8 & 700.8 & 700.8 & 700.8 & 700.8 & 700.8 & 700.8 & 700.8 & 700.8 & 700.8 & 700.8 \\
\hline Probability of Occurrence & 0.0105 & 0.0525 & 0.014 & 0.0128 & 0.0383 & 0.0102 & 0.0128 & 0.0368 & 0.0268 & 0.0116 & 0.0347 & 0.0116 & 0.0126 & 0.7152 \\
\hline
\end{tabular}

\subsection{Results and Discussion}

\subsubsection{Operational Results of First Phase Model}

GAMS 23.6.2 software has been utilized to solve the provided model for Greece resilient oil supplier selection. According to Torabi \& Hassini (2008), in order to use TH approach first of all, pay-off table must be confounded as Table 10 .

Table 10

Pay-off table for Greece resilient oil supplier selection problem

\begin{tabular}{cccc}
\hline & Oil Dependency (\%) & $\mathrm{HHI}_{3}$ & CVaR (billion dollars) \\
\hline Oil Dependency & 66.41 & 0.61 & 83.45 \\
$\mathrm{HHI}_{3}$ & 10.62 & 0 & 86.172 \\
$\mathrm{CVaR}$ & 47.2 & 0.656 & 51.277 \\
$\mathrm{PIS}$ & 66.41 & 0 & 51.277 \\
$\mathrm{NIS}$ & 10.62 & 0.656 & 86.172 \\
\hline
\end{tabular}

It is notable that over this section, $\alpha$ is considered as 0.95 . Moreover in order to use TH approach for solving a multi-objective problem, importance weight of each objective ( $\left.w_{i}\right)$ must be determined in addition to a weight for minimum satisfaction level of all objectives $(\gamma)$. Therefor the importance weights of Oil Dependency, $\mathrm{HHI}_{3}$ and $\mathrm{CVaR}$ are considered as 0.3, 0.6 and 0.1 respectively. Detailed and practical results for $\gamma=0.5$ are provided in

Table 11. According to achieved plan, oil-supply contracts must be signed with Algeria, Kuwait, Libya, Qatar, Russia and Saudi Arabia. Also among all candidate ports, five ports are selected by the proposed model to be prepared for receiving oil: Korinthos, Pireas, Preveza, Thessaloniki and Volos. Consequently mentioned plan results in $50.42 \%$ for weighted average oil-dependency of suppliers, 0.198 units of co-vary diversity and 61.822 billion dollars as its CVaR. As observed, provided model in this study results in a contingency plan which not only mitigates political and economic risks, but also reduces catastrophic risks remarkably by a negligible increase in initial and infrastructural costs. To see details of scenarios 1 to 13 , refer to Table 6 . Note that the $14^{\text {th }}$ scenario denotes the regular condition.

\subsubsection{Operational Results of Second Phase Model}

In this section, according to the selected ports and share of each one resulting from first phase, proposed model for assigning location and capacity of oil-storage terminals has been solved for Euclidean $(p=2)$ distance measure. It is notable that algorithm parameters are as follows: $\tau=0.05, C R=0.35, N P=300$ and $G_{\max }=1500$. By considering distances as straight lines (Euclidean), optimum number of oil-storage terminals is 5 and characteristics of each terminal have been provided in Table 12 and graphical view 
of obtained results are depicted in Fig. 4. Also, the flow of achieving optimum solution by proposed algorithm has been illustrated in Fig. 5.

\section{Table 11}

Annual oil-supply plan of Greece under each scenario

\begin{tabular}{|c|c|c|c|}
\hline Scenario & Supplier & Port & Number of oil-carrying trucks \\
\hline \multirow{4}{*}{1} & Kuwait & Pireas & 2150 \\
\hline & Libya & Korinthos & 3323 \\
\hline & Qatar & Korinthos & 1698 \\
\hline & Saudi Arabia & Pireas & 1892 \\
\hline \multirow{5}{*}{2} & Algeria & Korinthos & 1819 \\
\hline & Kuwait & Thessaloniki & 1809 \\
\hline & Libya & Volos & 2838 \\
\hline & Qatar & Pireas & 1250 \\
\hline & Saudi Arabia & Korinthos & 1346 \\
\hline \multirow{4}{*}{3} & Kuwait & Thessaloniki & 2206 \\
\hline & Libya & Korinthos & 3103 \\
\hline & Qatar & Pireas & 1839 \\
\hline & Saudi Arabia & Pireas & 1915 \\
\hline \multirow{5}{*}{4} & Algeria & Pireas & 1511 \\
\hline & Kuwait & Thessaloniki & 1865 \\
\hline & Libya & Korinthos & 2469 \\
\hline & Qatar & Korinthos & 1594 \\
\hline & Saudi Arabia & Pireas & 1623 \\
\hline \multirow{5}{*}{5} & Algeria & Korinthos & 1523 \\
\hline & Kuwait & Thessaloniki & 1870 \\
\hline & Libya & Korinthos & 2425 \\
\hline & Qatar & Korinthos & 1622 \\
\hline & Saudi Arabia & Volos & 1622 \\
\hline \multirow{5}{*}{6} & Algeria & Pireas & 1667 \\
\hline & Kuwait & Volos & 1879 \\
\hline & Libya & Korinthos & 2843 \\
\hline & Qatar & Preveza & 1093 \\
\hline & Saudi Arabia & Volos & 1581 \\
\hline \multirow{6}{*}{7} & Algeria & Korinthos & 1858 \\
\hline & Kuwait & Pireas & 1672 \\
\hline & Libya & Korinthos & 1753 \\
\hline & Qatar & Thessaloniki & 948 \\
\hline & Russia & Volos & 1512 \\
\hline & Saudi Arabia & Volos & 1320 \\
\hline \multirow{4}{*}{8} & Algeria & Pireas & 1919 \\
\hline & Kuwait & Thessaloniki & 3768 \\
\hline & Libya & Korinthos & 720 \\
\hline & Russia & Volos & 2656 \\
\hline \multirow{4}{*}{9} & Algeria & Korinthos & 1787 \\
\hline & Kuwait & Thessaloniki & 4182 \\
\hline & Libya & Korinthos & 448 \\
\hline & Russia & Thessaloniki & 2646 \\
\hline \multirow{5}{*}{10} & Algeria & Korinthos & 2235 \\
\hline & Kuwait & Volos & 2205 \\
\hline & Libya & Korinthos & 666 \\
\hline & Russia & Thessaloniki & 2088 \\
\hline & Saudi Arabia & Pireas & 1870 \\
\hline \multirow{4}{*}{11} & Algeria & Volos & 2657 \\
\hline & Kuwait & Thessaloniki & 2647 \\
\hline & Libya & Korinthos & 533 \\
\hline & Russia & Thessaloniki & 3227 \\
\hline \multirow{5}{*}{12} & Algeria & Korinthos & 2347 \\
\hline & Kuwait & Thessaloniki & 2376 \\
\hline & Libya & Korinthos & 266 \\
\hline & Russia & Volos & 2123 \\
\hline & Saudi Arabia & Volos & 1949 \\
\hline \multirow{4}{*}{13} & Algeria & Pireas & 2583 \\
\hline & Kuwait & Thessaloniki & 3437 \\
\hline & Libya & Korinthos & 213 \\
\hline & Russia & Thessaloniki & 2830 \\
\hline \multirow{5}{*}{14} & Algeria & Korinthos & 1743 \\
\hline & Kuwait & Thessaloniki & 1812 \\
\hline & Libya & Preveza & 2747 \\
\hline & Qatar & Pireas & 1329 \\
\hline & Saudi Arabia & Volos & 1432 \\
\hline
\end{tabular}


Table 12

Geographic position and capacity of each oil-storage terminals, considering Euclidean distance measure

\begin{tabular}{cccc}
\hline No. & Longitude & Latitude & Capacity (Barrels) \\
\hline 1 & 23.71 & 37.97 & 14700000 \\
2 & 22.96 & 40.64 & 7350000 \\
3 & 20.75 & 38.96 & 7350000 \\
4 & 22.93 & 37.94 & 7350000 \\
5 & 22.94 & 39.36 & 7350000 \\
\hline
\end{tabular}

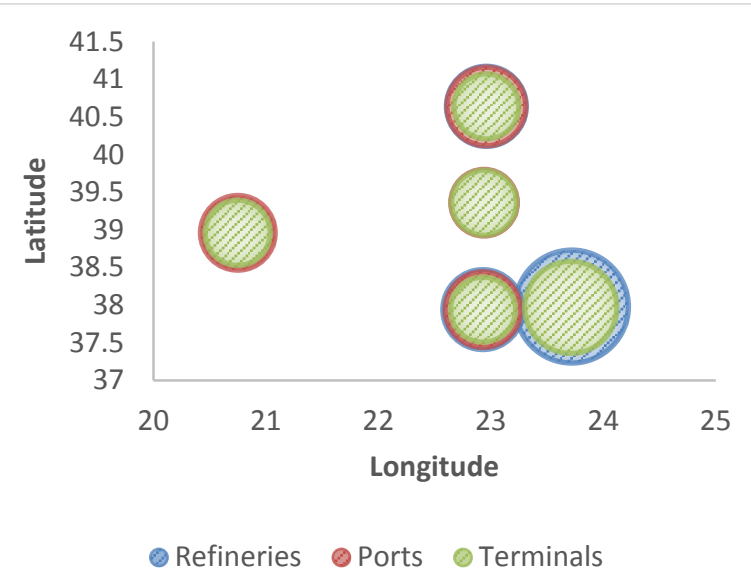

Fig. 4. Graphical view of ports, terminals and refineries considering Euclidean distance measure

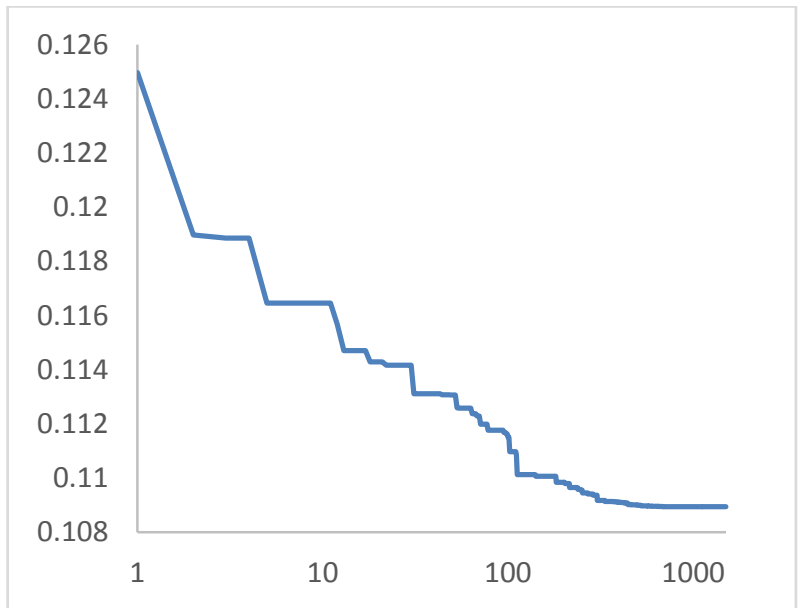

Fig. 5. The procedure of obtaining optimum solution by the proposed DE algorithm

\subsubsection{Sensitivity Analysis}

Fig. 6 illustrates variation in satisfaction degree of each objective corresponding to variation of $\gamma$, which proves efficiency of utilized approach. Because despite wide range of changes in $\gamma$, satisfaction degrees do not vary substantially and balanced solutions are achieved.

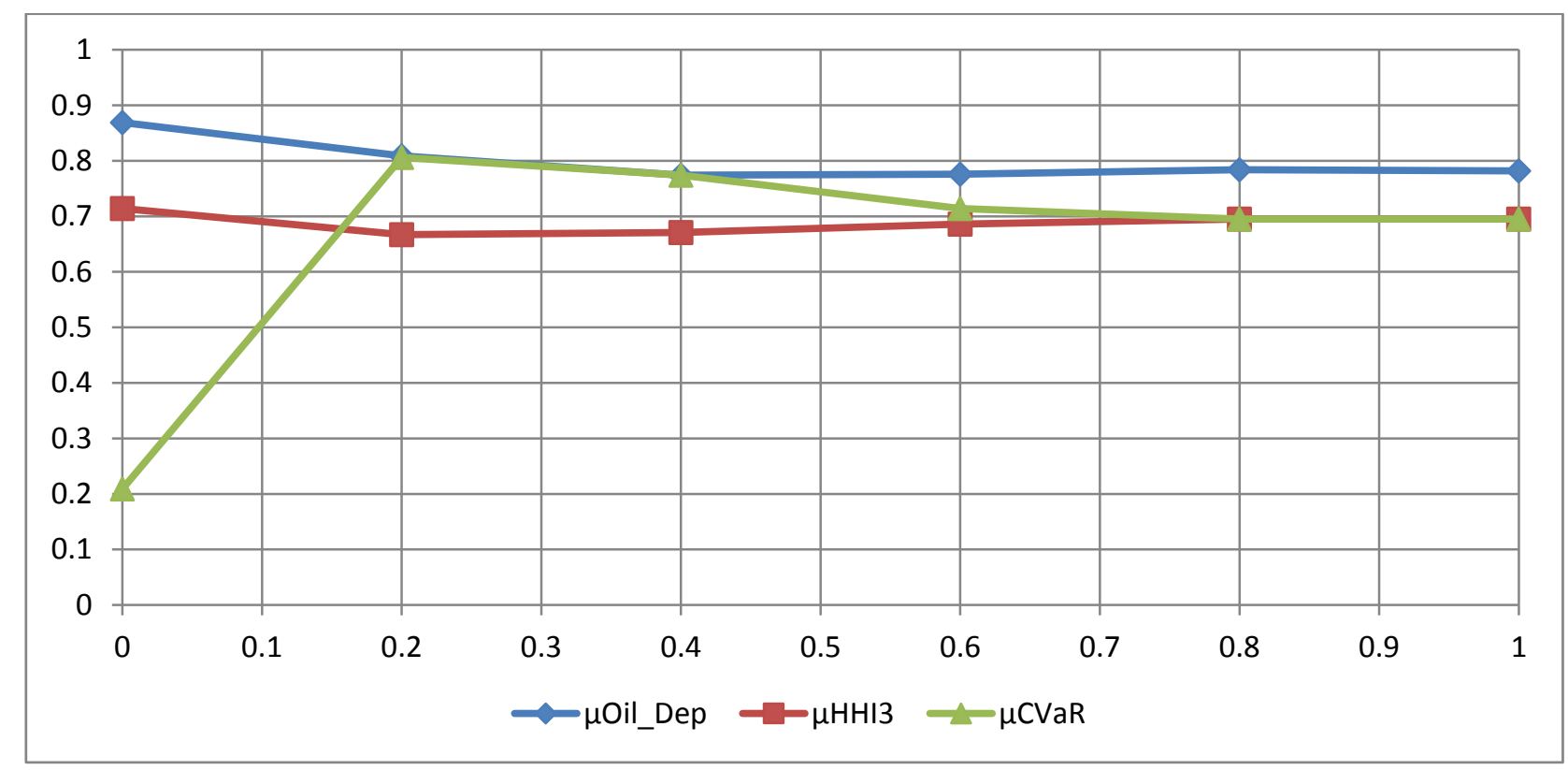

Fig. 6. Variation of satisfaction degrees regarding to changes in $\gamma$ 
There are two key parameters ( $\alpha$ and $D_{\text {em }}$ min which must be assigned by decision maker. Therefore model has been run for different values of $\alpha$ and Dem $_{\min }$, then their interaction and their impact on each objective are investigated.

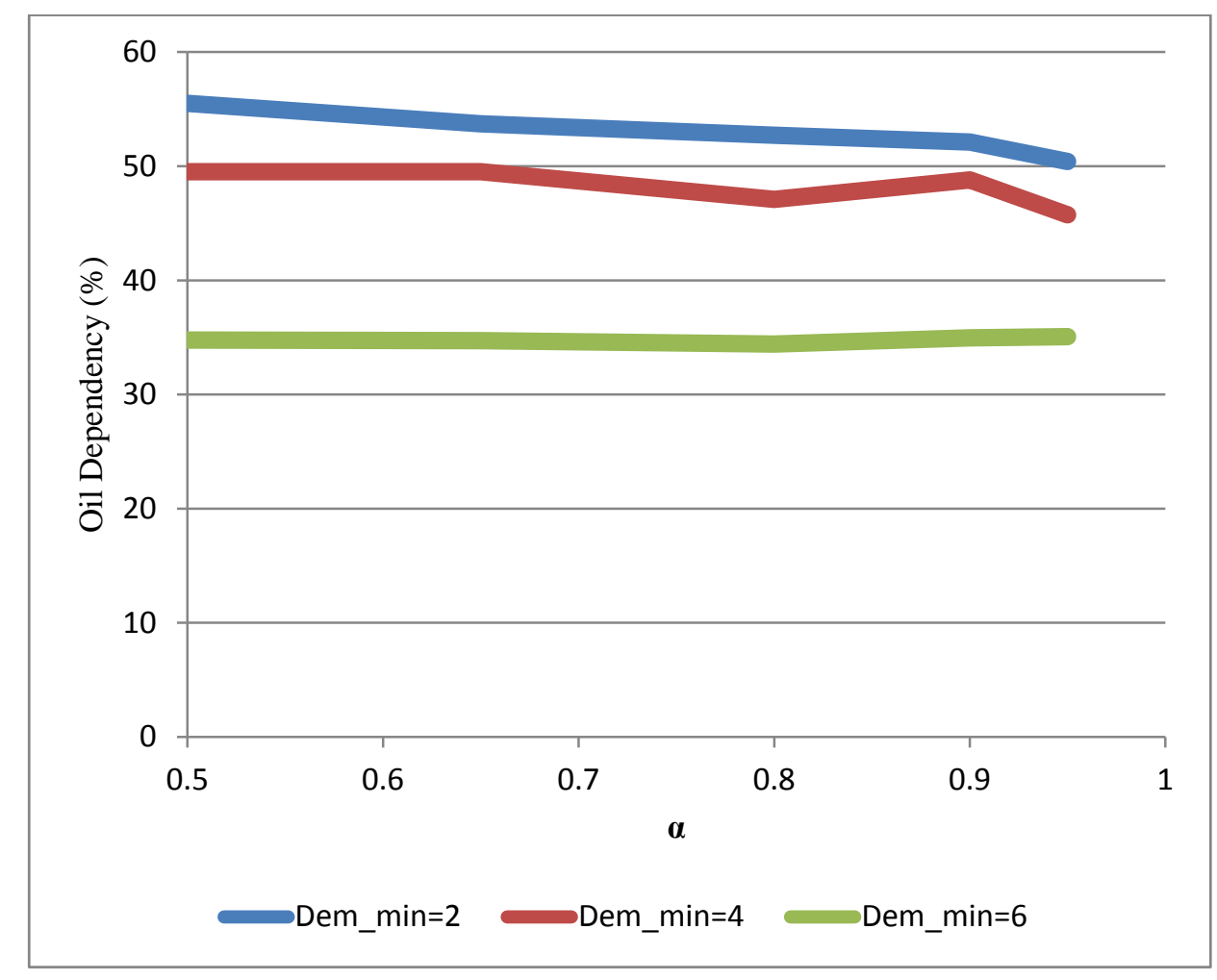

Fig. 7. Variation of oil-dependency corresponding to variation of $\alpha$ and Dem $\min$

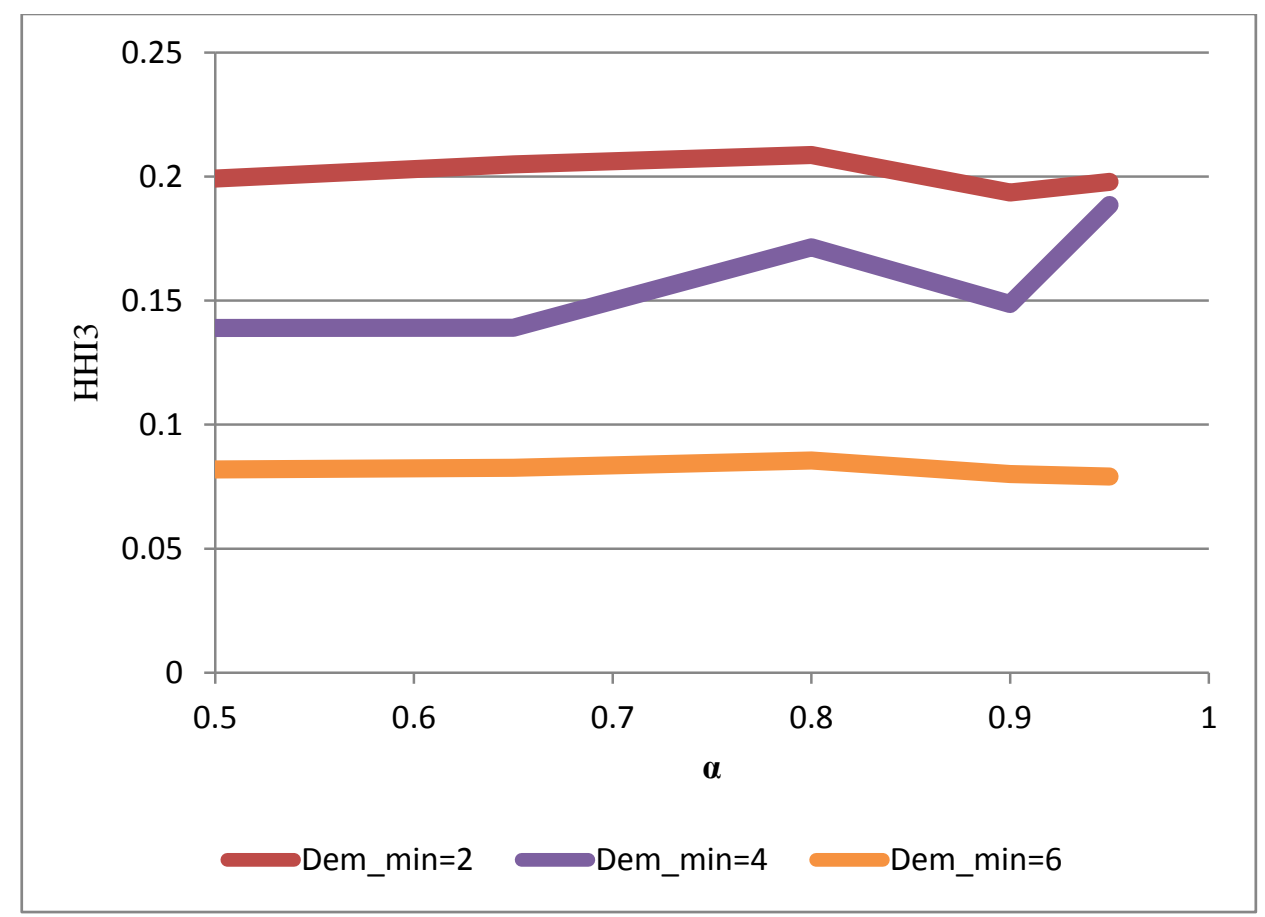

Fig. 8. Variation of co-vary diversity index corresponding to variation of $\alpha$ and Dem $\min$ 


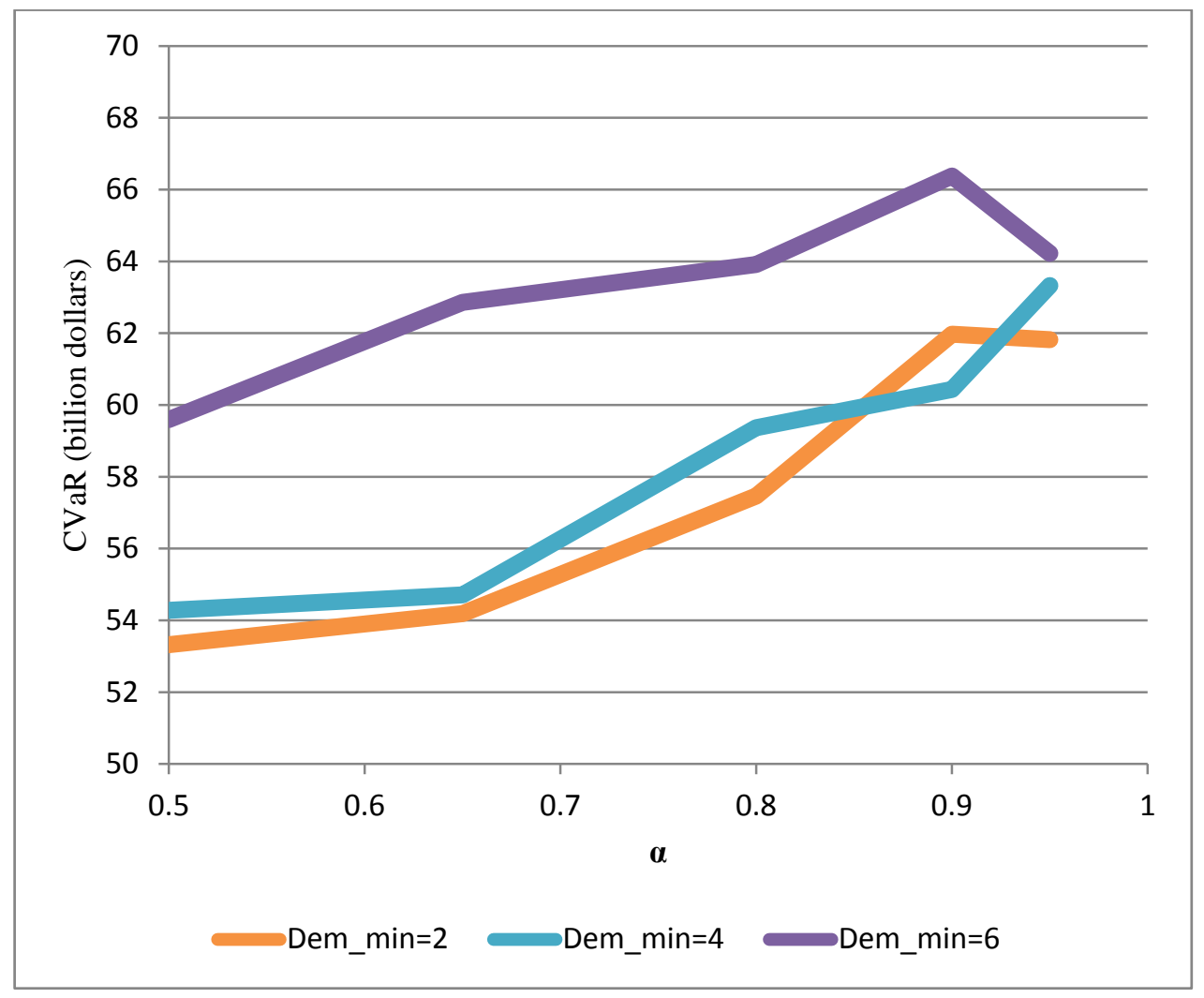

Fig. 9. Variation of Conditional Value at Risk corresponding to variation of $\alpha$ and Dem $_{\text {min }}$

$\checkmark$ Fig. 7 illustrates that a plan with larger minimum level of democracy results in lower dependency of selected supplier countries to oil-export incomes and consequently decreases geopolitical bargaining power of oil-importer. So decision maker(s) must establish a balance between level of political development and economic dependency of selected oil-suppliers.

$\checkmark$ Fig. 8 proves that democracy leads to resiliency. Because as minimum level of democracy increases, mutual conflict between suppliers and importer decreases.

$\checkmark$ Fig. 7 and Fig. 8 show that large minimum level of democracy results in plans which have negligible sensitivity to $\alpha$. Therefore as selected suppliers perform better in field of interior affairs in their own countries, more consistent oil-supply plans can be achieved.

$\checkmark$ Fig. 9 confirms statement declared by Haimes (2004) that suggests small investments for structure improvement which leads to significant mitigation in catastrophic risks. Regarding to Fig. 9, less than 20\% increase in structural costs results in more than $45 \%$ decrease in catastrophic risks.

$\checkmark \quad$ Fig. 8 and Fig. 9 depict that however increasing minimum democracy level incurs more cost to an oil-importer, this increase leads to higher level of stability in proposed plan; in other words: you gain as you pay.

\section{Conclusion and Future Research}

After a comprehensive multidisciplinary survey about oil security, supplier selection and risk management; it has been found out that there is a broad research gap in field of selecting a resilient portfolio of oil suppliers. Therefore authors have provided a novel quantitative approach for oil supplier selection in order to overcome oil-supply disruption. Proposed model in the first phase of this study not only takes technical requirements and limitations of oil procurement into account, but also considers qualitative factors such as democracy and political conflicts by using their quantitative indicators. On one hand resiliency is satisfied by taking catastrophic risks into account using scenario-based CVaR 
approach and on the other hand resiliency is guaranteed by considering political, economic and financial issues simultaneously.

For the proposed model in the second phase, a continuous facility layout model has been provided for determining location and capacity of oil-storage terminals. The proposed model enhances security of oil-storage terminals network by maximizing their dispersion, in addition to improve efficiency of network by minimizing distances between entry, storage and refining ports. Due to the complexity of proposed CFLP model, a meta-heuristic algorithm based on Differential Evolution (DE) has been proposed for solving the mentioned model. Finally validity of proposed models is proved by solving it for Greece case problem. Further investigations show that plans with higher political quality are remarkably more consistent.

In future studies, social unrests in oil exporter countries can be taken into account. Moreover by prevalence of environmental issues, it is appropriate to consider emission-related factors. Furthermore a similar study can be performed on portfolio of energies comprising oil, natural gas and oil-products.

\section{References}

Beccue, P.C., \& Huntington, H.G. (2005). An assessment of oil market disruption risks. Final Report EMF SR, 8.

Berle, Ø., Norstad, I., \& Asbjørnslett, B.E. (2013). Optimization, risk and resilience in LNG transportation systems. Supply Chain Management: An International Journal, 18(3), 253-264.

Blum, H., \& Legey, L.F.L. (2012). The challenging economics of energy security: Ensuring energy benefits in support to sustainable development. Energy Economics, 34(6), 1982-1989. doi: http://dx.doi.org/10.1016/j.eneco.2012.08.013

Briggs, C.A., Tolliver, D., \& Szmerekovsky, J. (2012). Managing and mitigating the upstream pertoleum industry supply chain risks: leveraging analytic hierarchy process. International Journal of Business \& Economics Perspectives, 7(1), 1-20.

Brown, S.P., \& Kennelly, R.T. (2013). Consequences of US dependence on foreign oil: National Energy Policy Institute.

Chuang, M.C., \& Ma, H.W. (2013). Energy security and improvements in the function of diversity indices-Taiwan energy supply structure case study. Renewable and Sustainable Energy Reviews, 24, 9-20.

CIA. (2009). The World Factbook. Washington, DC: Central Intelligence Agency.

Clarke, L., Krey, V., Weyant, J., \& Chaturvedi, V. (2012). Regional energy system variation in global models: Results from the Asian Modeling Exercise scenarios. Energy Economics, 34, Supplement 3(0), S293-S305. doi: http://dx.doi.org/10.1016/j.eneco.2012.07.018

Das, S., Leiby, P., Lee, R., Hadder, G., \& Davis, R. (1990). Oil markets under political and military stress. Energy Economics, 12(3), 204-210.

DoD, U. (2000). MIL-STD-882D standard practice for system safety program requirement.

Economist. (2010). Democracy index 2010. Democracy in retreat. Economist Intelligence Unit, 16, 145.

EconomyWatch.). Retrieved 2013], from http://www.economywatch.com/economicstatistics/economic-indicators/Value_Oil_Exports/2012

Grossi, P., \& Kunreuther, H. (2005). Catastrophe modeling: A new approach to managing risk (Vol. 25): Springer.

Haimes, Y.Y. (2004). Risk modeling, assessment, and management (Vol. 30): Wiley-Interscience.

Haldar, A., Ray, A., Banerjee, D., \& Ghosh, S. (2012). A hybrid MCDM model for resilient supplier selection. International Journal of Management Science and Engineering Management, 7(4), 284292.

Ho, W., Xu, X., \& Dey, P.K. (2010). Multi-criteria decision making approaches for supplier evaluation and selection: A literature review. European Journal of Operational Research, 202(1), 16-24. 
IEA. (2007). Oil Supply Security: Emergency Response of IEA Countries: International Energy Agency.

Jansen, J., Van Arkel, W., \& Boots, M. (2004). Designing indicators of long-term energy supply security: Energy research Centre of the Netherlands ECN.

Jewell, J. (2011). The IEA Model of Short-Term Energy Security (MOSES): Primary Energy Sources and Secondary Fuels. IEA Energy Papers.

Johansson, B. (2013). A broadened typology on energy and security. Energy, 53, 199-205.

Le Coq, C., \& Paltseva, E. (2009). Measuring the security of external energy supply in the European Union. Energy Policy, 37(11), 4474-4481.

Lesbirel, S.H. (2013). The Insuring State: Japanese Oil Import Security and the Middle East. Asian Journal of Political Science, 21(1), 41-61.

Manole, A., Bichir, V., Bodislav, A., Bardasu, G., \& Baltac, A.G. (2013). Guaranteeing Energy Supplies. Romanian Statistical Review Supplement, 61(2), 30-34.

Mansson, A., Johansson, B., \& Nilsson, L. (2012, 9-12 May 2012). Methodologies for characterising and valuing energy security-A short critical review. Paper presented at the European Energy Market (EEM), 2012 9th International Conference on the European Energy Market, Florence School of Regulation.

Mityakov, S., Tang, H., \& Tsui, K.K. (2012). International Politics and Import Diversification in the Second Wave of Globalization. CENTRO STUDI LUCA D'AGLIANO.

Morrow, J.D., Siverson, R.M., \& Tabares, T.E. (1998). The political determinants of international trade: The major powers, 1907-90. American Political Science Review, 92(3), 649-661.

OECD. (2007). Energy Security and Climate Policy-Assessing Interactions: Organisation for Economic Co-operation and Development.

Pachiu, L.V. (2013). The new meaning of national security concept from the energy perspective. Impact Strategic(1), 128-137.

Pasqualetti, M.J., \& Sovacool, B.K. (2012). The importance of scale to energy security. Journal of Integrative Environmental Sciences, 9(3), 167-180.

Pettit, T.J. (2008). Supply chain resilience: development of a conceptual framework, an assessment tool and an implementation process. (Ph.D), DTIC Document.

Pootakham, T., \& Kumar, A. (2010). Bio-oil transport by pipeline: A techno-economic assessment. Bioresource technology, 101(18), 7137-7143.

Rockafellar, R.T., \& Uryasev, S. (2002). Conditional value-at-risk for general loss distributions. Journal of Banking \& Finance, 26(7), 1443-1471. doi: http://dx.doi.org/10.1016/S03784266(02)00271-6

Sawik, T. (2010). Single vs. multiple objective supplier selection in a make to order environment. Omega, 38(3), 203-212.

Sawik, T. (2011a). Selection of a dynamic supply portfolio in make-to-order environment withrisks. Computers \& Operations Research, 38(4), 782-796.

Sawik, T. (2011b). Supplier selection in make-to-order environment with risks. Mathematical and Computer Modelling, 53(9), 1670-1679.

Shaffer, B. (2013). Natural gas supply stability and foreign policy. Energy Policy, 56, 114-125.

Sovacool, B.K., \& Mukherjee, I. (2011). Conceptualizing and measuring energy security: a synthesized approach. Energy, 36(8), 5343-5355.

Sovacool, B.K., Mukherjee, I., Drupady, I.M., \& D’Agostino, A.L. (2011). Evaluating energy security performance from 1990 to 2010 for eighteen countries. Energy, 36(10), 5846-5853.

Storn, R., \& Price, K. (1997). Differential evolution-a simple and efficient heuristic for global optimization over continuous spaces. Journal of global optimization, 11(4), 341-359.

Torabi, S.A., \& Hassini, E. (2008). An interactive possibilistic programming approach for multiple objective supply chain master planning. Fuzzy Sets and Systems, 159(2), 193-214. doi: 10.1016/j.fss.2007.08.010

Voeten, A.S.E. (2012-08). United Nations General Assembly Voting Data. Retrieved from: http://hdl.handle.net/1902.1/12379 
Yadlin, A., \& Guzansky, Y. (2012). The Strait of Hormuz: Assessing and Neutralizing the Threat. Strategic Assessment, 14, 7-22.

Zeng, A.Z., Berger, P.D., \& Gerstenfeld, A. (2005). Managing the Supply-Side Risks in Supply Chains: Taxonomies, Processes, and Examples of Decision-Making Modeling. Applications of Supply Chain Management and E-Commerce Research, 92, 141-160.

Zhang, H.-Y., Ji, Q., \& Fan, Y. (2013). An Evaluation Framework for Oil Import Security Based on the Supply Chain with a Case Study Focused on China. Energy Economics, 38, 87-95.

\section{Appendices}

Table A. 1

Characteristics of major oil exporters

\begin{tabular}{ccccc}
\hline No. & Oil exporter & $\begin{array}{c}\text { Oil-Dependency (Share of Oil } \\
\text { Export income in GDP)* }\end{array}$ & $\begin{array}{c}\text { Length of Pipeline } \\
\text { to Greece }\end{array}$ & $\begin{array}{c}\text { Democracy } \\
\text { Score** }\end{array}$ \\
\hline 1 & Algeria & $33.96 \%$ & 1830 & 3.44 \\
\hline 2 & Angola & $59.71 \%$ & 5315 & 3.32 \\
\hline 3 & India & $3.87 \%$ & 5005 & 7.28 \\
\hline 4 & Iran & $12.28 \%$ & 3170 & 1.94 \\
\hline 5 & Iraq & $44.15 \%$ & 1930 & 4 \\
\hline 6 & Kazakhstan & $28.74 \%$ & 3970 & 3.3 \\
\hline 7 & Kuwait & $61.08 \%$ & 2400 & 3.88 \\
\hline 8 & Libya & $74.47 \%$ & 1110 & 1.94 \\
\hline 9 & Malaysia & $9.03 \%$ & 8730 & 6.19 \\
\hline 10 & Norway & $10.62 \%$ & 2600 & 9.8 \\
\hline 11 & Qatar & $59.29 \%$ & 2970 & 3.09 \\
\hline 12 & Russian Federation & $14.03 \%$ & 2230 & 4.26 \\
\hline 13 & Saudi Arabia & $48.16 \%$ & 2630 & 1.84 \\
\hline 14 & UAE & $32.54 \%$ & 3255 & 2.52 \\
\hline 15 & USA & $0.79 \%$ & 8250 & 8.18 \\
\hline * EconomyWatch ** Fconomist(2010) & & & \\
\hline
\end{tabular}

Table A. 2

Mutual conflicts between major oil suppliers

\begin{tabular}{|c|c|c|c|c|c|c|c|c|c|c|c|c|c|c|c|}
\hline & Algeria & Angola & India & Iran & Iraq & Kazakhstan & Kuwait & Libya & Malaysia & Norway & Qatar & Russian Federation & Saudi Arabia & UAE & USA \\
\hline Algeria & 0.869 & 0.000 & 0.107 & 0.034 & 0.066 & 0.033 & 0.032 & 0.034 & 0.031 & 0.453 & 0.032 & 0.039 & 0.065 & 0.032 & 1.736 \\
\hline Angola & & 0.844 & 0.122 & 0.077 & 0.035 & 0.000 & 0.035 & 0.036 & 0.035 & 0.391 & 0.036 & 0.045 & 0.036 & 0.000 & 1.708 \\
\hline India & & & 0.844 & 0.077 & 0.075 & 0.118 & 0.073 & 0.080 & 0.073 & 0.500 & 0.073 & 0.136 & 0.109 & 0.074 & 1.733 \\
\hline Iran & & & & 0.960 & 0.070 & 0.111 & 0.034 & 0.036 & 0.034 & 0.596 & 0.000 & 0.128 & 0.000 & 0.035 & 1.878 \\
\hline Iraq & & & & & 0.750 & 0.035 & 0.000 & 0.034 & 0.032 & 0.440 & 0.000 & 0.122 & 0.000 & 0.000 & 1.654 \\
\hline Kazakhstan & & & & & & 0.750 & 0.034 & 0.073 & 0.067 & 0.431 & 0.034 & 0.080 & 0.070 & 0.000 & 1.640 \\
\hline Kuwait & & & & & & & 0.782 & 0.000 & 0.000 & 0.462 & 0.000 & 0.078 & 0.000 & 0.000 & 1.660 \\
\hline Libya & & & & & & & & 0.782 & 0.000 & 0.553 & 0.000 & 0.085 & 0.000 & 0.035 & 1.720 \\
\hline Malaysia & & & & & & & & & 0.750 & 0.491 & 0.000 & 0.077 & 0.000 & 0.032 & 1.667 \\
\hline Norway & & & & & & & & & & 0.000 & 0.471 & 0.391 & 0.480 & 0.431 & 1.087 \\
\hline Qatar & & & & & & & & & & & 0.800 & 0.080 & 0.000 & 0.000 & 1.692 \\
\hline Russian Federation & & & & & & & & & & & & 0.739 & 0.083 & 0.080 & 1.644 \\
\hline Saudi Arabia & & & & & & & & & & & & & 0.782 & 0.000 & 1.720 \\
\hline UAE & & & & & & & & & & & & & & 0.740 & 1.692 \\
\hline USA & & & & & & & & & & & & & & & 0.957 \\
\hline
\end{tabular}


Table A. 3

Probable excess capacity of major oil suppliers in regular condition Beccue \& Huntington (2005)

\begin{tabular}{ccc}
\hline Region & Excess Capacity $\left(\right.$ MMDB $\left.^{*}\right)$ & Probability \\
\hline \multirow{3}{*}{ Saudi Arabia } & 0 & 0.1 \\
& 1.5 & 0.75 \\
& 3 & 0.1 \\
\hline \multirow{3}{*}{ Other Persian Gulf } & 5 & 0.05 \\
& 0 & 0.7 \\
& 1 & 0.2 \\
\hline
\end{tabular}

Table A. 4

Excess capacity of Persian Gulf countries under each scenario

\begin{tabular}{|c|c|c|c|c|c|c|c|c|c|c|c|c|c|c|}
\hline Exporter & 1 & 2 & 3 & 4 & 5 & 6 & 7 & 8 & 9 & 10 & 11 & 12 & 13 & 14 \\
\hline Iran & 0.089 & 0.089 & 0.089 & 0.056 & 0.056 & 0.056 & 0.056 & 0.089 & 0.056 & 0.089 & 0.089 & 0.089 & 0.089 & 0.111 \\
\hline Iraq & 0.076 & 0.076 & 0.076 & 0.048 & 0.048 & 0.048 & 0.048 & 0.076 & 0.048 & 0.076 & 0.076 & 0.076 & 0.076 & 0.095 \\
\hline Kuwait & 0.074 & 0.074 & 0.074 & 0.047 & 0.047 & 0.047 & 0.047 & 0.074 & 0.047 & 0.074 & 0.074 & 0.074 & 0.074 & 0.093 \\
\hline Qatar & 0.037 & 0.037 & 0.037 & 0.023 & 0.023 & 0.023 & 0.023 & 0.037 & 0.023 & 0.037 & 0.037 & 0.037 & 0.037 & 0.046 \\
\hline Saudi Arabia & 1.591 & 1.591 & 1.591 & 1.591 & 1.591 & 1.591 & 1.591 & 1.340 & 1.340 & 0.838 & 0.838 & 0.838 & 0.168 & 1.675 \\
\hline UAE & 0.084 & 0.084 & 0.084 & 0.053 & 0.053 & 0.053 & 0.053 & 0.084 & 0.053 & 0.084 & 0.084 & 0.084 & 0.084 & 0.105 \\
\hline
\end{tabular}

Table A. 5

Approximate freight cost of one truck from oil-exporters to each port

\begin{tabular}{cccccccc}
\hline & Korinthos & Messolongi & Patra & Pireas & Preveza & Thessaloniki & Volos \\
\hline Algeria & 572500 & 660000 & 625000 & 607500 & 695000 & 782500 & 712500 \\
\hline Angola & 1792250 & 1879750 & 1844750 & 1827250 & 1914750 & 2002250 & 1932250 \\
India & 1764250 & 1886750 & 1869250 & 1746750 & 1904250 & 1694250 & 1729250 \\
Iran & 1122000 & 1244500 & 1227000 & 1104500 & 1262000 & 1052000 & 1087000 \\
Iraq & 702000 & 789500 & 772000 & 667000 & 807000 & 632000 & 649500 \\
\hline Kazakhstan & 1402000 & 1472000 & 1507000 & 1332000 & 1437000 & 1227000 & 1262000 \\
Kuwait & 866500 & 954000 & 936500 & 831500 & 971500 & 796500 & 814000 \\
Libya & 320500 & 408000 & 373000 & 355500 & 443000 & 530500 & 460500 \\
Malaysia & 3068000 & 3190500 & 3173000 & 3050500 & 3208000 & 2998000 & 3033000 \\
Norway & 964500 & 947000 & 982000 & 947000 & 859500 & 807000 & 842000 \\
Qatar & 1031000 & 1206000 & 1171000 & 996000 & 1276000 & 1066000 & 1013500 \\
Russian Federation & 842000 & 877000 & 912000 & 807000 & 772000 & 667000 & 702000 \\
Saudi Arabia & 912000 & 1087000 & 1052000 & 877000 & 1157000 & 947000 & 894500 \\
\hline UAE & 1130750 & 1305750 & 1270750 & 1095750 & 1375750 & 1165750 & 1113250 \\
\hline USA & 2854500 & 2802000 & 2767000 & 2872000 & 2837000 & 2977000 & 2924500 \\
\hline
\end{tabular}


Table A. 6

Construction cost of each pipeline category from each oil-exporter (\$)

\begin{tabular}{cccc}
\hline & $100000 \mathrm{MMDB}$ & $200000 \mathrm{MMDB}$ & $400000 \mathrm{MMDB}$ \\
\hline Algeria & 768600000 & 1244400000 & 2013000000 \\
\hline Angola & 2232300000 & 3614200000 & 5846500000 \\
\hline India & 2102100000 & 3403400000 & 5505500000 \\
Iran & 1331400000 & 2155600000 & 3487000000 \\
\hline Iraq & 810600000 & 1312400000 & 2123000000 \\
Kazakhstan & 1667400000 & 2699600000 & 4367000000 \\
Kuwait & 1008000000 & 1632000000 & 2640000000 \\
Libya & 466200000 & 754800000 & 1221000000 \\
Malaysia & 36666000000 & 5936400000 & 9603000000 \\
Norway & 1092000000 & 1768000000 & 2860000000 \\
Qatar & 1247400000 & 2019600000 & 3267000000 \\
Russian Federation & 936600000 & 1516400000 & 2453000000 \\
Saudi Arabia & 1104600000 & 1788400000 & 2893000000 \\
UAE & 1367100000 & 2213400000 & 3580500000 \\
USA & 3465000000 & 5610000000 & 9075000000 \\
\hline
\end{tabular}

